\title{
A numerical model of the structural behavior of buckling-restrained braces
}

\author{
F. López-Almansa ${ }^{1}$, J.C. Castro-Medina ${ }^{2}$, S. Oller ${ }^{3}$ \\ ${ }^{1}$ Technical University of Catalonia, Architecture Structures Department, Avda. Diagonal 649, 08028 Barcelona, Spain \\ ${ }^{2}$ Technical University of Catalonia, Department of Geotechnical Engineering and Geosciences, Campus Nord UPC, 08034 \\ Barcelona, Spain \\ ${ }^{3}$ Technical University of Catalonia, Strength of Materials and Engineering Structures Department, Campus Nord UPC, \\ 08034 Barcelona, Spain
}

\begin{abstract}
This work presents a numerical model of the cyclic structural behavior of dissipative buckling-restrained braces, commonly used as an alternative to classical concentric braces for seismic protection of building frames and other structures. Such devices are usually composed of a slender steel core embedded in a stockiest casing that is intended to prevent its buckling when it is under compression. The casing is made either of mortar or steel, and a sliding interface is interposed between the core and the casing to prevent excessive shear stress transfer. The behavior of the steel core is described by a damage and plasticity model; the behavior of the mortar casing is described by an isotropic damage model and the sliding behavior of the interface is described by a contact penalty model. These three models are implemented in the Abaqus software package following an explicit formulation. The ability of this algorithm to reproduce the cyclic behavior of buckling-restrained braces is verified in a number of representative yet simple situations. The accuracy of the proposed model is checked by comparison with experimental results; a satisfactory agreement is obtained. Preliminary conclusions are issued and further research needs are identified.
\end{abstract}

KEY WORDS: Energy dissipators, buckling-restrained braces, passive control, numerical simulation, damage model, plasticity.

\section{Introduction}

Energy dissipators are a convenient option for earthquake-resistant design of buildings and other civil engineering constructions since these devices absorb most of the input energy thus protecting the main structure from damage even under strong seismic motions [Housner et al., 1997; Soong, Dargush, 1997]; many applications have been reported [Martelli, 2006]. Several types of devices have been proposed; those based on plastification of metals (commonly termed as hysteretic) are simple, economical and reliable while have shown repeatedly their usefulness. Among them, the buckling-restrained braces are one of the dissipators that have been mostly used, mainly for seismic protection of building frames [Watanabe et al., 1988; Clark et al., 1999]. They consist of slender steel bars connected usually to the frame to be protected either like concentric diagonal braces or like concentric chevron braces (as shown by Figure 1(a)). Under horizontal seismic excitations, the inter-story drift motion generates axial strains in such steel bars beyond their yielding points. The buckling of these core bars is prevented by embedding them in a stockiest encasing; such casing is usually composed either of steel elements [Iwata, 2004; Tsai et al., 2004] or of mortar coated with steel (see Figure 1(b)). Some sliding interface between the steel core and the surrounding material is required to prevent excessive shear stress transfer, since it would reduce the longitudinal stress in the core thus impairing the energy dissipation capacity. As well, that interface involves some clearance between the core and the mortar; such gap is required to allow the Poisson expansion of the core during compression.

Correspondence to: F. López-Almansa e-mail: francesc.lopez-almansa@,upc.edu, phone +34-93-4016316, +34-606807733, FAX +34-93-4016320. 


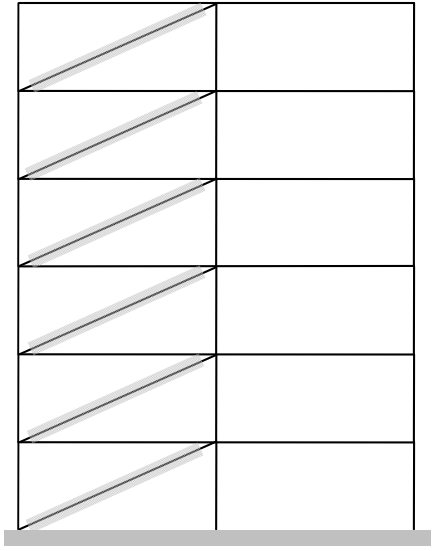

(a) Protected building frames

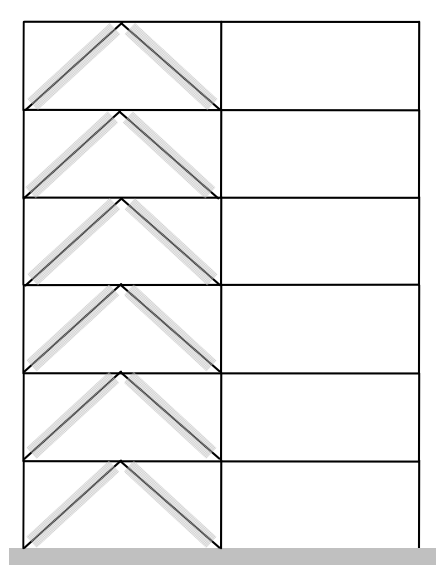

Figure 1. Buckling-restrained braces

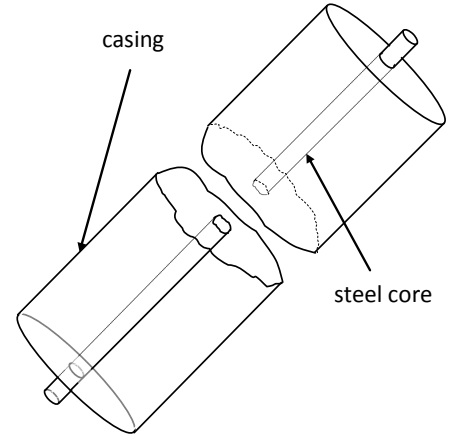

(b) Detail of a device

The buckling-restrained braces possess several relevant advantages compared to other hysteretic devices:

- These dissipators constitute themselves a bracing system and no additional braces are required to connect each device to the main frame.

- Since the dissipative part of the device can encompass near the whole length of the brace, the required strain is rather low. Therefore, the plastic excursions are moderate; as the degree of plastification is uniform along the whole body of the core, expectedly the fatigue resistance will be high.

- A relevant experience is available since a number of individual and sub-assemblage tests have been carried out [Tsai et al., 2004; Black et al., 2004; López et al. 2004; Tremblay et al. 2006; Wada, Nakashima; 2004; Lee, Bruneau, 2005; D'Aniello et al. 2006; Newell et al. 2006] and many realizations have been reported, mostly in Japan [Iwata, 2004], Taiwan [Tsai et al., 2004], Canada [Tremblay et al., 1999] and the United States [Black et al., 2004]. Preliminary versions of design codes have been proposed [Kasai, Kibayashi, 2004; Kibayashi et al., 2004; Sabelli, Aiken, 2004] and many references about design procedures are available [Tremblay et al. 2006; Wada, Nakashima, 2004; Fahnestock et al. 2004; Astrella, Whittaker, 2005; Sabelli et al. 2005; Choi, Kim, 2006].

- The ratio between the dissipated energy and the added material is the highest in the comparative devices [Palazzo et al. 2004]; such added material comprises the dissipators, the rest of the bracing system and the connections.

In spite of the aforementioned relevant existing background about the buckling-restrained braces, there are still some open questions dealing mainly with the numerical modeling of the buckling behavior of these devices. The buckling design of the mortar-steel coating is based usually in simplified second-order formulations [Black et al., 2004; Wada, Nakashima, 2004] whose parameters usually are not selected from the actual characteristics of the device but mainly from semi-empirical considerations; hence, such models are not highly accurate and might yield unsafe results. In the references [Palazzo et al., 2009; Palazzo et al., 2011], approximate expressions of the critical axial force and maximum bending moment in the casing are derived in terms of the actual axial force and the initial eccentricities the core and of the casing; the accuracy of this formulation is checked by comparison with experimental results. The reference [Chou, Chen, 2010] presents a similar study for buckling-restrained braces whose sliding interface consists of a small air gap. In that work, a finite element model of the cyclic behavior of the considered devices is derived; this model is implemented in the computer program Abaqus [Abaqus, 2006]. The von 
Mises yielding criterion was considered in the steel core and restraining members; the cyclic effects were described by a combined isotropic and kinematic hardening model. The behavior of the concrete was assumed to be elastic. The sliding interaction between the steel core and the restraining members was modeled as a hard contact behavior, allowing separation of the interface in tension and no penetration in compression; a friction coefficient equal to 0.1 was adopted to simulate greasy steel interfaces.

Apart from these rather simplified models, an accurate and comprehensive numerical model of the coupled nonlinear behavior of all the involved elements (steel core, casing and sliding interface) has not yet been proposed. This lack hinders the deep understanding of the structural behavior of these devices, compels that the design is based on uncertain and over-conservative approaches and prevents the proposal of innovative and daring solutions. This work aims to close this gap by proposing an accurate and reliable numerical finite element model of the structural behavior of buckling-restrained braces composed of a steel core surrounded by a mortar and steel casing. This model considers the joint behavior of the involved materials (inner and outer steel, mortar and sliding interface) and accounts for the partial sliding between the core and the encasing mortar. The buckling behavior of the steel core is described by a coupled damage and plasticity model formulated for large displacements; the behavior of the mortar casing is described by an isotropic damage model and the sliding behavior of the interface is described by a contact penalty model. These three models are jointly implemented in the Abaqus software package [Abaqus, 2006] following an explicit formulation; the resulting combined model is aimed to describe the structural behavior of buckling-restrained braces and constitutes the main contribution of this work. The ability of the three individual models to simulate the corresponding behaviors and the capacity of the combined model to reproduce the cyclic behavior of buckling-restrained braces are verified in a number of simple yet representative situations. The accuracy of the proposed algorithm is checked by comparison with two sets of available experimental results [Palazzo et al., 2009; Newell, Uang, Benzoni, 2006]; satisfactory agreements are obtained. Arising from these studies, relevant conclusions are issued and further research needs are identified.

This work belongs to a research project that aims to promote the mass use of patent-free buckling-restrained braces for seismic protection of buildings in developing countries. The research approach consists of: (i) designing, producing and testing individually short length dissipators (about $400 \mathrm{~mm}$ long) [Palazzo et al., 2006; Palazzo et al., 2011], (ii) taking profit of the gained experience to design, produce and test individually larger prototype devices (near 3000 $\mathrm{mm}$ long) [Palazzo et al., 2009], (iii) deriving a simplified model of the buckling behavior of these devices [Palazzo et al., 2009], (iv) developing an accurate numerical model of their structural behavior, (v) designing, producing and testing on subassemblies a number of full scale dissipators and (vi) performing a numerical parametric study about the seismic efficiency of such devices. The first three stages are completed while the last three ones are still in progress; this paper deals mainly with the fourth stage. It is expected that the proposed model will allow designing devices that are more slender than the currently available ones; such devices might be less costly and, hence, more suitable for mass use in developing countries.

\section{Isotropic damage model for the mortar casing}

The behavior of the mortar casing is described by a triaxial isotropic damage model. Damage models [Lubliner et al., 1989] consist basically of describing the degradation of the material by a scalar damage index $d$ ranging between 0 (no damage) and 1 (destruction):

$$
\sigma=(1-d) \sigma_{0}=(1-d) \mathrm{E}_{0}: \varepsilon
$$


In this constitutive relation tensors $\sigma$ and $\varepsilon$ represent stresses and strains, respectively; $\sigma_{0}$ is the undamaged stress tensor and $\mathbf{E}_{0}$ contains the undamaged values of the constitutive parameters. Equation 1 shows that the undamaged behavior is described by a linear elastic multiaxial model; damage arises when $F(\tau, r)=G(\tau)-G(r)$ ceases to be negative, where $r$ is the damage threshold and $\tau$ is an energy norm. Function $G$ governs the evolution of the damage threshold $r$; an exponential law is chosen [Lubliner et al., 1989]:

$$
G(r)=1-\frac{r}{r_{0}} e^{C\left(1-\frac{r}{r_{0}}\right)}
$$

Since the degradation is irreversible, $r$ decreases continuously after its initial value $r_{0}=f_{\mathrm{t}} /(E)^{1 / 2}$ [Castro-Medina, 2011] where $E$ is the initial deformation modulus and $f_{t}$ is the mortar tensile strength. $C$ is a dimensionless positive parameter given by [Simo and Ju, 1987]

$$
C=\left(\frac{G_{\mathrm{f}}^{*} E}{l^{*} f_{\mathrm{t}}^{2}}-\frac{1}{2}\right)^{-1}
$$

In this equation $G_{\mathrm{f}}^{*}=G_{\mathrm{f}} l^{*}$ where $G_{\mathrm{f}}$ is the fracture energy per unit area and $l^{*}$ is a characteristic length of the finite elements used in the discretization [Oliver, 1989]. The energy norm is defined accounting for the different values of the compressive $\left(f_{\mathrm{c}}\right)$ and tensile strengths [Castro-Medina, 2011] as:

$$
\tau=\left(\theta+\frac{1-\theta}{f_{\mathrm{c}} / f_{\mathrm{t}}}\right) \sqrt{\sigma_{\mathbf{0}}: \mathrm{E}_{\mathbf{0}}^{-1}: \sigma_{\mathbf{0}}}
$$

In this definition $\theta$ is a scalar variable ranging between 0 for triaxial compression and 1 for triaxial tension [Castro-Medina, 2011]. The loading and unloading behavior is governed by the well-known Kuhn-Tucker conditions [Simo, Hughes, 1998]:

$$
\dot{\mu} \geq 0 \quad F(\tau, r) \leq 0 \quad \dot{\mu} F(\tau, r)=0
$$

$\mu$ is a damage consistency parameter given by $\dot{r}=\dot{\mu}$.

In the proposed formulation the damage problem is solved by an iterative algorithm [Castro-Medina, 2011].

The ability of this model to describe the nonlinear behavior of mortar members is verified in the simple yet representative situation described by Figure 2. Figure 2 shows a prismatic mortar rod that is clamped in one of their ends and undergoes imposed axial displacements in its other end.

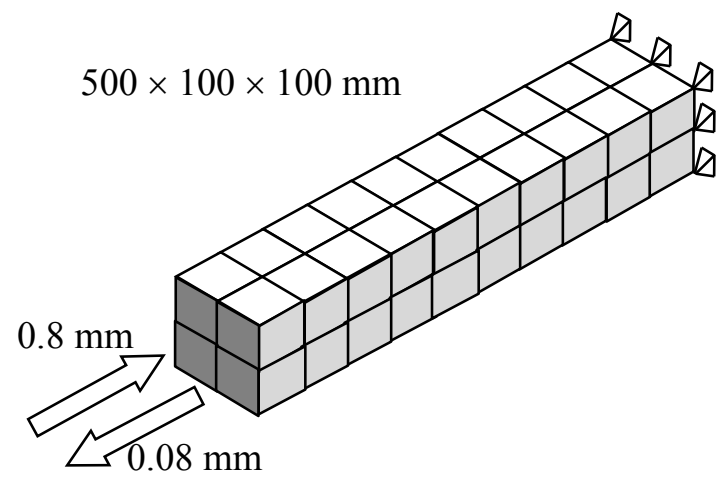

Figure 2. Mortar member under imposed axial displacements 
The bar is $500 \mathrm{~mm}$ long and the cross section is square with $100 \mathrm{~mm}$ side; such stocky design (slenderness $\lambda=34.64$ ) prevents the risk of relevant buckling. As shown by Figure 2, the bar is discretized by 8-node hexahedron Lagrangian elements. The main mechanical parameters of the mortar are: compressive strength $39.92 \mathrm{MPa}$, tensile strength $3.99 \mathrm{MPa}$, Poisson's ratio 0.2 and deformation modulus $17.52 \mathrm{GPa}$. The fracture energy per unit area is $G_{\mathrm{f}}=0.104 \mathrm{MPa}$ and the characteristic length $l^{*}$ is equal to the side of the finite element. The imposed displacements consist of two ramp functions with final amplitudes 0.8 and $0.08 \mathrm{~mm}$ in shortening (compression) and in elongation (tension), respectively. Figure 3 shows the obtained results for the outer finite element; in Figure 3 and in the subsequent ones, positive values correspond to tension and to elongation. Plots from Figure 3 depict a regular behavior.

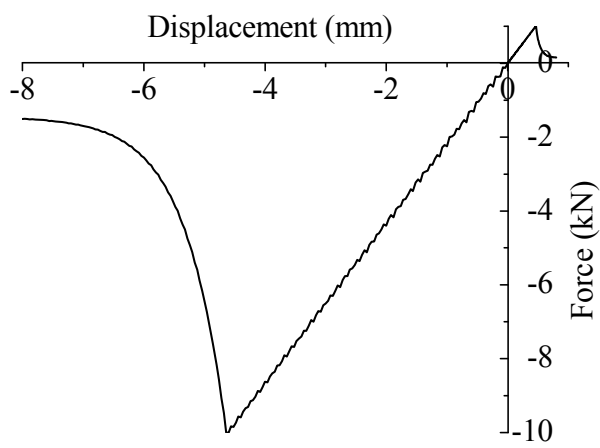

Figure 3. Numerical simulation of the stress-strain behavior of mortar

\section{Damage and plasticity model for the steel core}

The cyclic buckling behavior of the steel core is described by a coupled damage and plasticity model; such model is formulated for large displacements, yet keeping small strains, to describe the buckling instability. The coupling between damage (stiffness degradation) and plasticity (permanent strains) has been previously pointed out [Armero and Oller, 2000]. However, both issues are rather different and cannot be described with the same constitutive model; this work presents a new formulation that considers jointly damage and plasticity. The coupling between them is only weak since each of these mechanisms has their own threshold functions, dissipation potentials, and consistency factors while the coupling is established through the effective stresses $\bar{\sigma}$; e.g. those distributed in the effective area $(1-d) A, A$ being the total area. The damage is described by the same model explained in the previous section. The damage initiates once the failure surface is reached; the plastic-damage behavior is governed by:

$$
\sigma=(1-d) \bar{\sigma}=(1-d) \mathbf{E}_{0}: \varepsilon^{\mathrm{e}}
$$

In this constitutive relation $\varepsilon^{\mathrm{e}}$ is the elastic part of the strain.

The plastic hardening can be described either by isotropic or kinematic models [Simo, Hughes, 1998]; the plastic behavior is governed by the classical conditions:

$$
F(\bar{\sigma}-\eta, \mathbf{q})=f(\bar{\sigma}-\eta)-\bar{f}_{y} \leq 0 \quad \dot{\gamma} \geq 0
$$

In these expressions $\eta$ is a hardening variable, $\mathbf{q}$ is an internal plastic variable, $\bar{f}_{y}$ is the updated yielding limit, $f$ is the yielding surface given by the multiaxial Von Mises criterion $(f(\bar{\sigma}-\eta)=$ $\left.\sqrt{\frac{3}{2} \operatorname{dev}(\bar{\sigma}-\eta): \operatorname{dev}(\bar{\sigma}-\eta)}\right)$ and $\gamma$ is a plastic consistency parameter given by $\dot{\varepsilon}_{\mathrm{p}}=\dot{\gamma} \frac{\partial F(\bar{\sigma}-\eta, q)}{\partial \bar{\sigma}}$ 
where $\dot{\varepsilon}_{\mathrm{p}}$ is the plastic strain rate.

The coupling between plasticity and damage is established in terms of the free Helmholtz energy:

$$
\Psi\left(\boldsymbol{\varepsilon}, \boldsymbol{\sigma}_{\mathrm{p}}, \mathbf{q}, d\right)=(1-d) \Psi_{0}(\boldsymbol{\varepsilon})-\boldsymbol{\varepsilon}: \boldsymbol{\sigma}_{\mathrm{p}}+\Psi_{\mathrm{p}}\left(\boldsymbol{\sigma}_{\mathrm{p}}, \mathbf{q}\right)
$$

$\boldsymbol{\sigma}_{\mathrm{p}}$ is the plastic stress, $\Psi_{0}$ is the energy corresponding to the undamaged state (being given by $\left.\Psi_{0}=\frac{1}{2} \varepsilon: \mathbf{E}_{0}: \varepsilon\right)$ and $\Psi_{\mathrm{p}}$ is a plastic potential. This formulation provides the values of the plastic consistency parameter and the tangent plastic tensor:

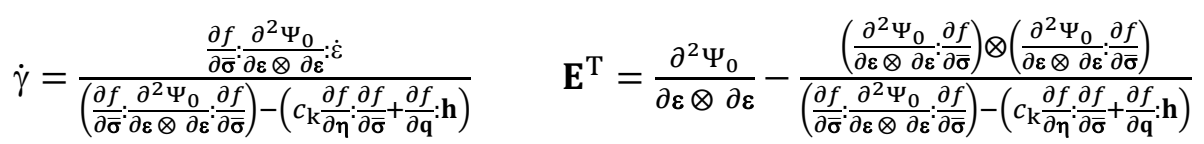

In these expressions $c_{\mathrm{k}}$ is a kinematic hardening variable and $\mathbf{h}$ is a vector given by $\mathbf{q}=\dot{\gamma} \mathbf{h}$.

In the proposed formulation the damage and plasticity problems are solved by a mapping return algorithm [Castro-Medina, 2011].

The ability of this model to describe the hysteretic behavior of steel members is verified in the simple representative situation described by Figure 4 . Figure 4 shows a prismatic steel rod that is clamped in one of their ends and undergoes an imposed axial displacement law in its other end.

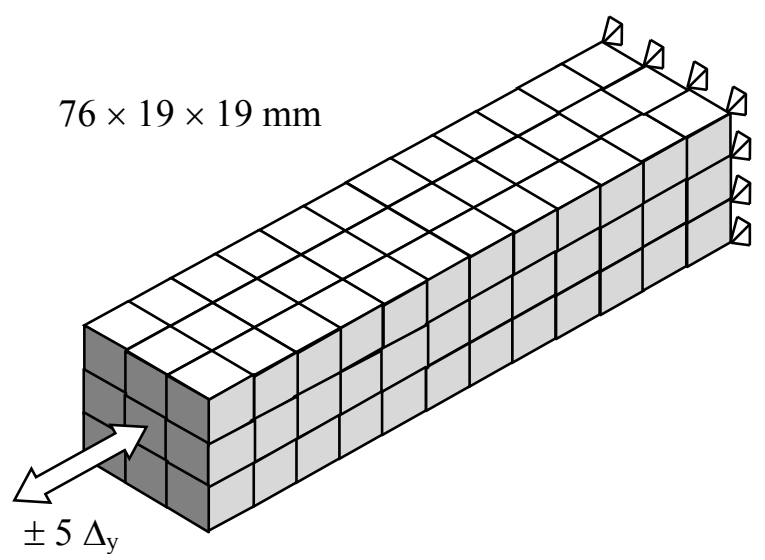

Figure 4. Steel member under imposed axial displacement

The bar is $76 \mathrm{~mm}$ long and the cross section is square with $19 \mathrm{~mm}$ side; as in the mortar bar (Figure 2), such stocky design (slenderness $\lambda=27.71$ ) prevents the risk of relevant buckling. As shown by Figure 4, the bar is discretized by 8 -node hexahedron Lagrangian elements. The steel type is S355 [EN 10025, 2002], whose nominal yielding point and ultimate strength are 355 and $470 \mathrm{MPa}$, respectively; the deformation modulus is $210 \mathrm{GPa}$ and the Poisson's ratio is 0.3 . Both kinematic and isotropic hardening have been considered; the kinematic hardening has been assumed as $H_{\mathrm{K}}=21 \mathrm{GPa}(E / 10)$ while the isotropic hardening has been assumed as $H_{\mathrm{I}}=21 \mathrm{GPa}$. No damage has been considered inside the model. The imposed displacements consist of a series of triangular waves with growing amplitudes $\pm 0.25 \Delta_{\mathrm{y}}, \pm 0.5 \Delta_{\mathrm{y}}, \pm 0.75 \Delta_{\mathrm{y}}, \pm \Delta_{\mathrm{y}}$ and $\pm 5 \Delta_{\mathrm{y}} ; \Delta_{\mathrm{y}}$ is the yielding displacement. Figure 5 depicts the obtained hysteresis loops. Plots from Figure 5(a) and Figure 5(b) correspond to regular kinematic and isotropic plastic behaviors, respectively. 


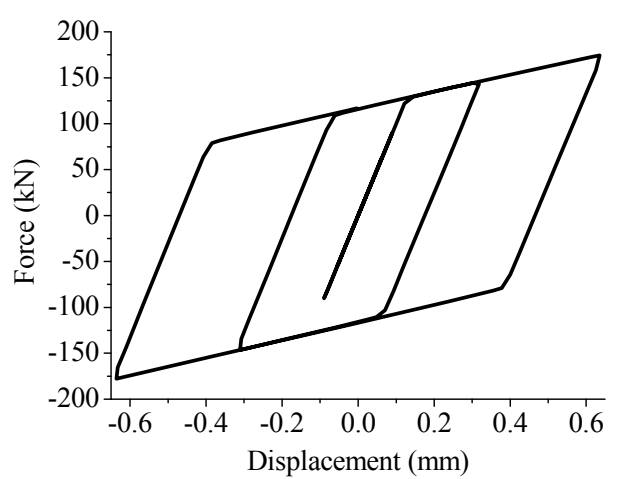

(a) Kinematic hardening

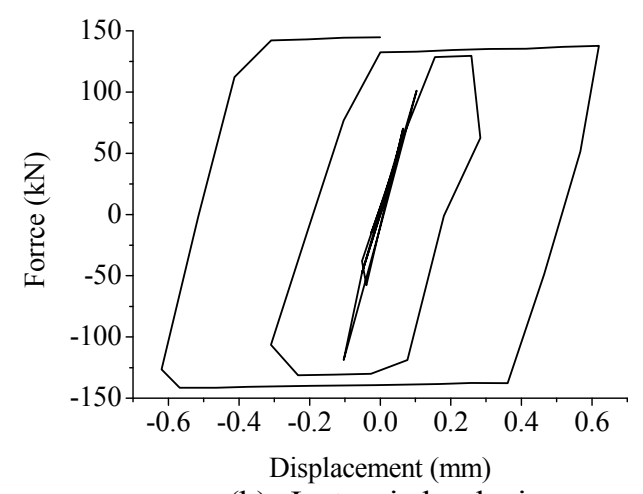

(b) Isotropic hardening

Figure 5. Numerical simulation of hysteresis loops in an axially deformed steel bar

\section{Penalty contact model for the sliding interface}

The sliding behavior of the interface between mortar and concrete is described by a penalty contact model [Wriggers, 2006]. The steel surface is considered as "penetrating master" while the mortar one is "penetrated slave"; the penetration is described with a penalty formulation by interposing a highly stiff spring between both surfaces. In the finite element discretization the contact has to be established node-to-node. The ensuing minimum-distance problem is solved by minimizing the total potential energy:

$$
\Pi=\frac{1}{2} \int_{\Gamma}\left(k_{\mathrm{n}} g_{\mathrm{n}}^{2}+k_{\mathrm{t}} g_{\mathrm{t}}^{2}\right) d A
$$

In this equation $\Gamma$ is the contact surface and $k_{\mathrm{n}}$ and $k_{\mathrm{t}}$ are positive normal and tangent penalty factors, respectively [Castro-Medina, 2011]. Scalars $g_{\mathrm{n}}$ and $g_{\mathrm{t}}$ correspond to the normal and tangent directions, respectively, and are given by

$$
g_{\mathrm{n}}=\left(\mathbf{x}_{\mathrm{m}}-\mathbf{x}_{\mathrm{s}}\right) \mathbf{n}_{\mathrm{s}} \quad g_{\mathrm{t}}=\int_{t_{0}}^{t}\|\ddot{\mathbf{u}} \dot{\xi}\| d t
$$

Vectors $\mathbf{x}_{\mathrm{m}}$ and $\mathbf{x}_{\mathrm{s}}$ represent the mortar and steel coordinates, respectively, and $\mathbf{n}_{\mathrm{s}}$ is a unit vector normal to the surface; $\ddot{\mathbf{u}}$ is the updated steel relative acceleration and $\dot{\xi}$ is the updated convective velocity. The contact and separation conditions are governed by the well-known Herz-Signori-Moreau conditions [Wriggers, 2006]:

$$
g_{\mathrm{n}} \geq 0 \quad p_{\mathrm{n}} \leq 0 \quad g_{\mathrm{n}} p_{\mathrm{n}}=0
$$

$p_{\mathrm{n}}$ represents the normal contact force:

$$
p_{\mathrm{n}}=\frac{k_{\varepsilon}}{k+k_{\varepsilon}}(k h-m g)
$$

In this equation $k$ is the equivalent spring constant, $k_{\varepsilon}$ is the penalty parameter (interposed spring constant), $h$ is the gap between both surfaces, $m$ is the mass associated to the node, and $g$ is the acceleration of gravity.

In the proposed formulation the contact problem is solved by an iterative algorithm [Castro-Medina, 2011]. 
The ability of this model to describe the sliding contact behavior is verified in a simple representative situation; it consists of a prismatic steel core embedded in a mortar casing as described by Figure 6 .

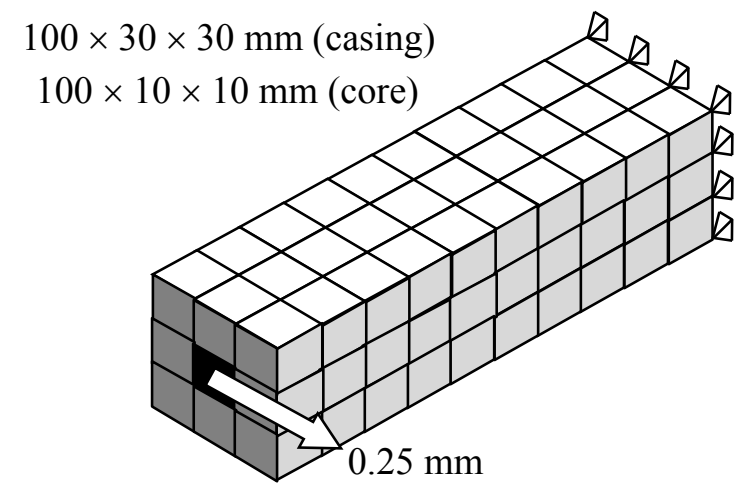

Figure 6. Simple buckling-restrained brace considered for verification purposes

Figure 6 depicts a square steel core with $10 \mathrm{~mm}$ side and a surrounding square mortar with $30 \mathrm{~mm}$ side; both elements are $100 \mathrm{~mm}$ long. As shown by Figure 6, the steel core and the mortar casing have been discretized by 8-node hexahedron Lagrangian elements; noticeably, the contact between steel and mortar is node-to-node. The sliding interface consists merely of an air gap being $0.12 \mathrm{~mm}$ wide. The steel type is S275 [EN 10025, 2002], whose nominal yielding point is $275 \mathrm{MPa}$ and whose ultimate strength is $410 \mathrm{MPa}$; the kinematic hardening has been assumed as $H_{\mathrm{K}}=20 \mathrm{GPa}$. The main mechanical parameters of the mortar are: compressive strength 39.92 $\mathrm{MPa}$, tensile strength $3.99 \mathrm{MPa}$, Poisson's ratio 0.2 and deformation modulus $17.52 \mathrm{GPa}$; the fracture energy per unit area is $G_{\mathrm{f}}=0.104 \mathrm{MPa}$. In the contact model the friction coefficient is $\kappa=$ 0.1 , the directionality is isotropic and there is no limit in the transfer of shear stresses. A transversal displacement is imposed to the core; it consists of a ramp function reaching $0.25 \mathrm{~mm}$, followed by a constant branch. Figure 7 depicts the obtained time history results of the transversal displacement of a pair of contact nodes. Figure 7 shows that before the contact the displacement of the mortar is zero and that after contact both nodes remain together; noticeably, the contact behavior is properly reproduced, without spurious vibrations.

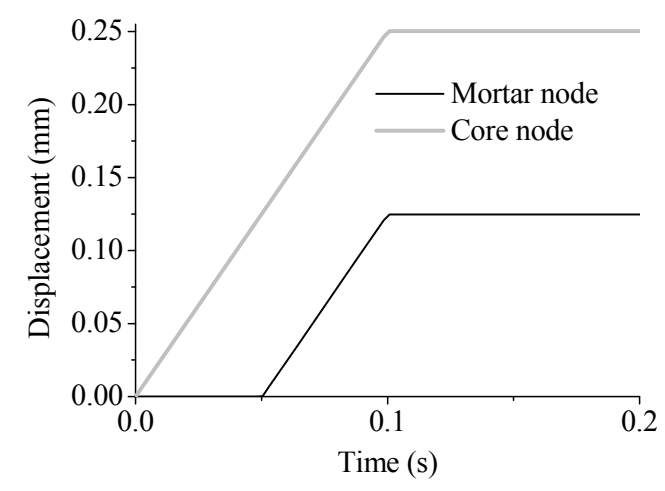

Figure 7. Numerical simulation of the sliding behavior of the contact interface

\section{Integrated model for the buckling-restrained brace}

The models described in the previous three sections are jointly implemented in the Abaqus 
software package [Abaqus, 2006]; the subsequent dynamic problem is solved following an explicit formulation. The resulting combined model is aimed to describe the overall structural behavior of buckling-restrained braces and constitutes the main outcome of this work. The explicit formulation is chosen because the stiffness matrix is ill-conditioned as a result of the penalty formulation of the contact model. The integration of the models of the mortar, the steel and the interface has been carried by imposing the energy balance equation:

$$
\int_{0}^{t}\left(\int_{V} \boldsymbol{\sigma}: \dot{\boldsymbol{\varepsilon}} d V\right) d t=\int_{0}^{t}\left(\int_{V} \boldsymbol{\sigma}: \dot{\boldsymbol{\varepsilon}}^{\mathrm{e}} d V\right) d t+\int_{0}^{t}\left(\int_{V} \boldsymbol{\sigma}: \dot{\boldsymbol{\varepsilon}}^{\mathrm{p}} d V\right) d t+\int_{0}^{t}\left(\int_{V} \boldsymbol{\sigma}: \dot{\boldsymbol{\varepsilon}}^{\mathrm{d}} d V\right) d t
$$

In this equation the left-hand side corresponds to the internal energy and the three terms in the right-hand side correspond to the elastic, plastic and damage energies, respectively. $\varepsilon^{\mathrm{d}}$ is the yielding strain tensor.

The ability of this integrated model to describe the cyclic behavior of buckling-restrained braces is verified on the simple device considered in the previous section (see Figure 6). The core undergoes six triangular cycles of growing imposed axial displacements; their amplitudes are $\pm \Delta_{\mathrm{y}}, \pm 2 \Delta_{\mathrm{y}}, \pm 3 \Delta_{\mathrm{y}}, \pm 5 \Delta_{\mathrm{y}}, \pm 10 \Delta_{\mathrm{y}}$ and $\pm 15 \Delta_{\mathrm{y}} ; \Delta_{\mathrm{y}}$ is the yielding displacement. The maximum amplitude is elected to generate plastification and damage in the steel core. Figure 8 displays the obtained monotonic behavior of the tensioned naked core (a) and of the compressed whole device (b) and Figure 9 displays the obtained hysteresis loops.

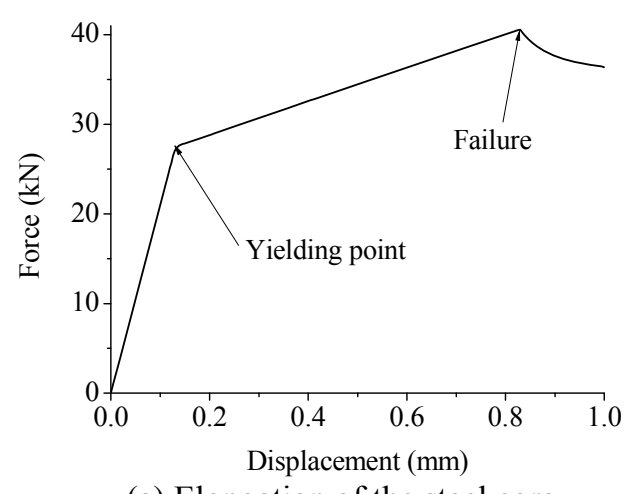

(a) Elongation of the steel core

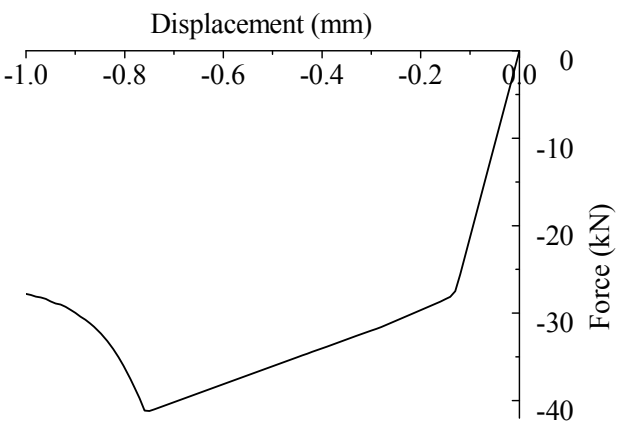

(b) Shortening of the overall device

Figure 8. Numerical simulation of the monotonic behavior

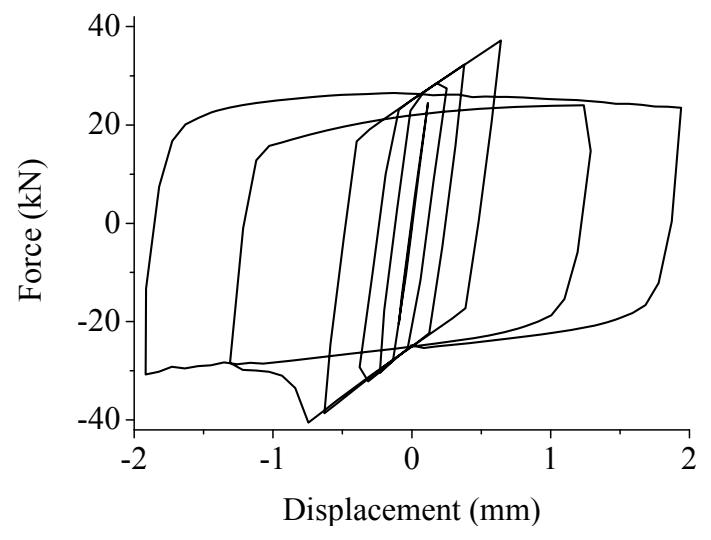

Figure 9. Numerical simulation of the hysteresis loops 
In Figure 8(a) and in Figure 8(b) the two corner points correspond successively to yielding and to failure of the steel core. Comparison between Figure 8 and Figure 9 shows that the monotonic behavior in Figure 8 can be also observed in the hysteresis loops in Figure 9.

\section{Comparison between numerical and experimental results}

The accuracy of the proposed model is checked by comparison with experimental results obtained in two series of tests carried out in the universities of Girona [Palazzo et al., 2009] and San Diego [Newell, Uang, Benzoni, 2006], respectively.

\subsection{Tests in the University of Girona}

These experiments consist of testing four buckling-restrained braces under imposed axial displacements until failure [Palazzo et al., 2009; Palazzo et al., 2011]. Such devices are shaped as shown by Figure 1(b), being basically composed of a slender solid bar (cylinder) as dissipative steel core and a round thin-wall steel tube filled with high strength mortar (without shrinkage) as restraining casing. Two two-halved steel connectors are placed at both ends to ensure a proper anchoring to the frame. The sliding is ensured by a three-layer interface: the steel core is coated with Teflon ${ }^{\circledR}$, lubricated with grease and wrapped with rubber. Figure 10 shows a plan view of the device, an elevation of one of their ends and two front views; the left front view includes a steel connector while the right one shows a bare core end [Palazzo et al., 2009]. These end connections are basically hinged.

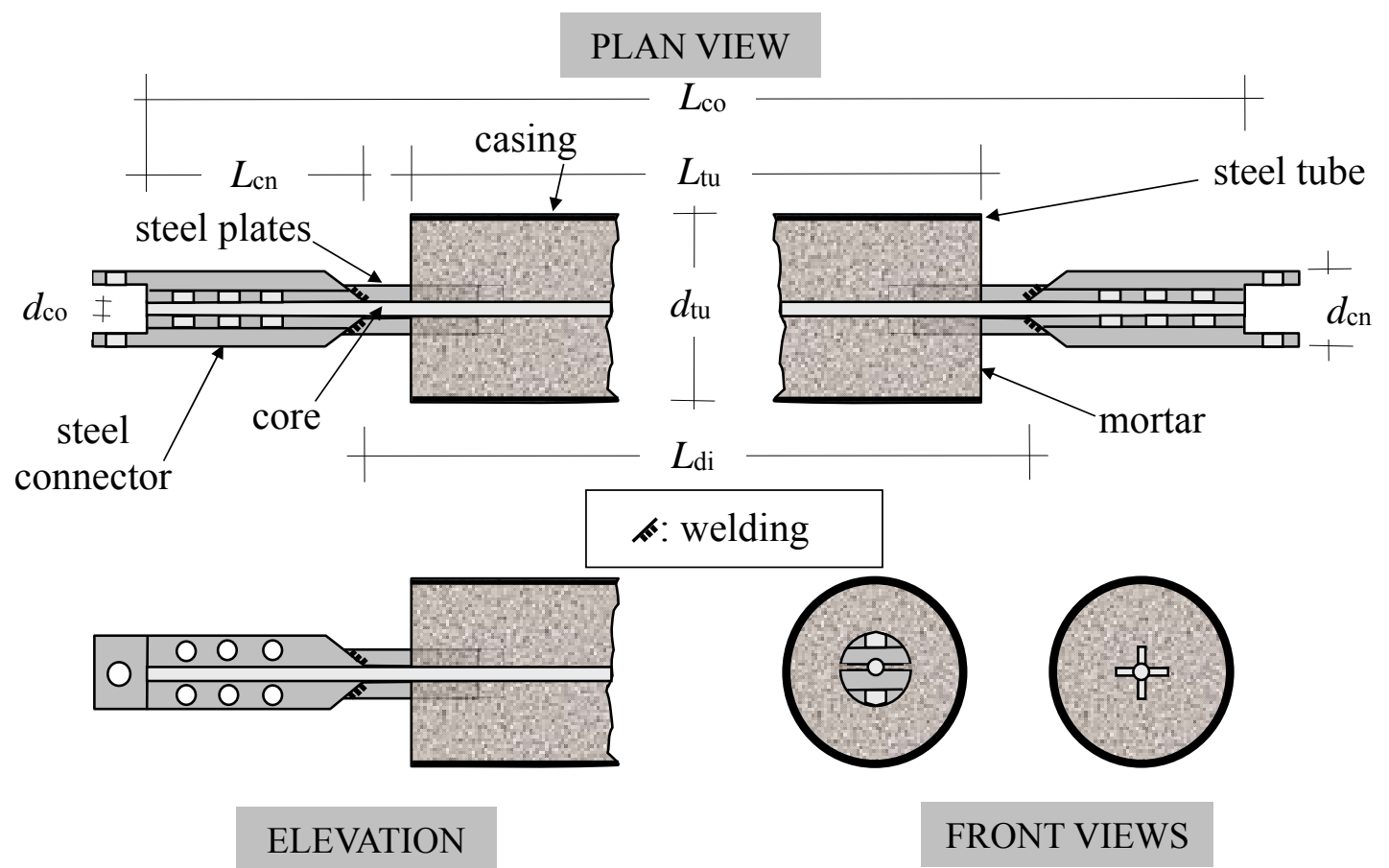

Figure 10. Buckling-restrained brace tested in the University of Girona [Palazzo et al., 2009]

The four tested devices are termed D1, D2, D3 and D4; the values of their geometrical parameters (Figure 10) are summarized in Table 1. 
Table 1. Main geometrical parameters of prototypes D1, D2, D3 and D4

\begin{tabular}{ccccccccc}
\hline Devices & $\begin{array}{c}L_{\mathrm{co}} \\
(\mathrm{mm})\end{array}$ & $\begin{array}{c}L_{\mathrm{cn}} \\
(\mathrm{mm})\end{array}$ & $\begin{array}{c}L_{\mathrm{tu}} \\
(\mathrm{mm})\end{array}$ & $\begin{array}{c}L_{\mathrm{di}} \\
(\mathrm{mm})\end{array}$ & $\begin{array}{c}d_{\mathrm{co}} \\
(\mathrm{mm})\end{array}$ & $\begin{array}{c}d_{\mathrm{tu}} \\
(\mathrm{mm})\end{array}$ & $\begin{array}{c}t_{\mathrm{tu}} \\
(\mathrm{mm})\end{array}$ & $\begin{array}{c}d_{\mathrm{cn}} \\
(\mathrm{mm})\end{array}$ \\
\hline D1 \& D2 & 2808 & 200 & 2422 & 2466 & 10 & 90 & 3 & 80 \\
& & & & & & & & 85
\end{tabular}

Table 1 shows that dissipators D1 and D2, as well as D3 and D4, are designed to be alike; this allows comparing their results. Figure 11 depicts the testing rig of device D1.

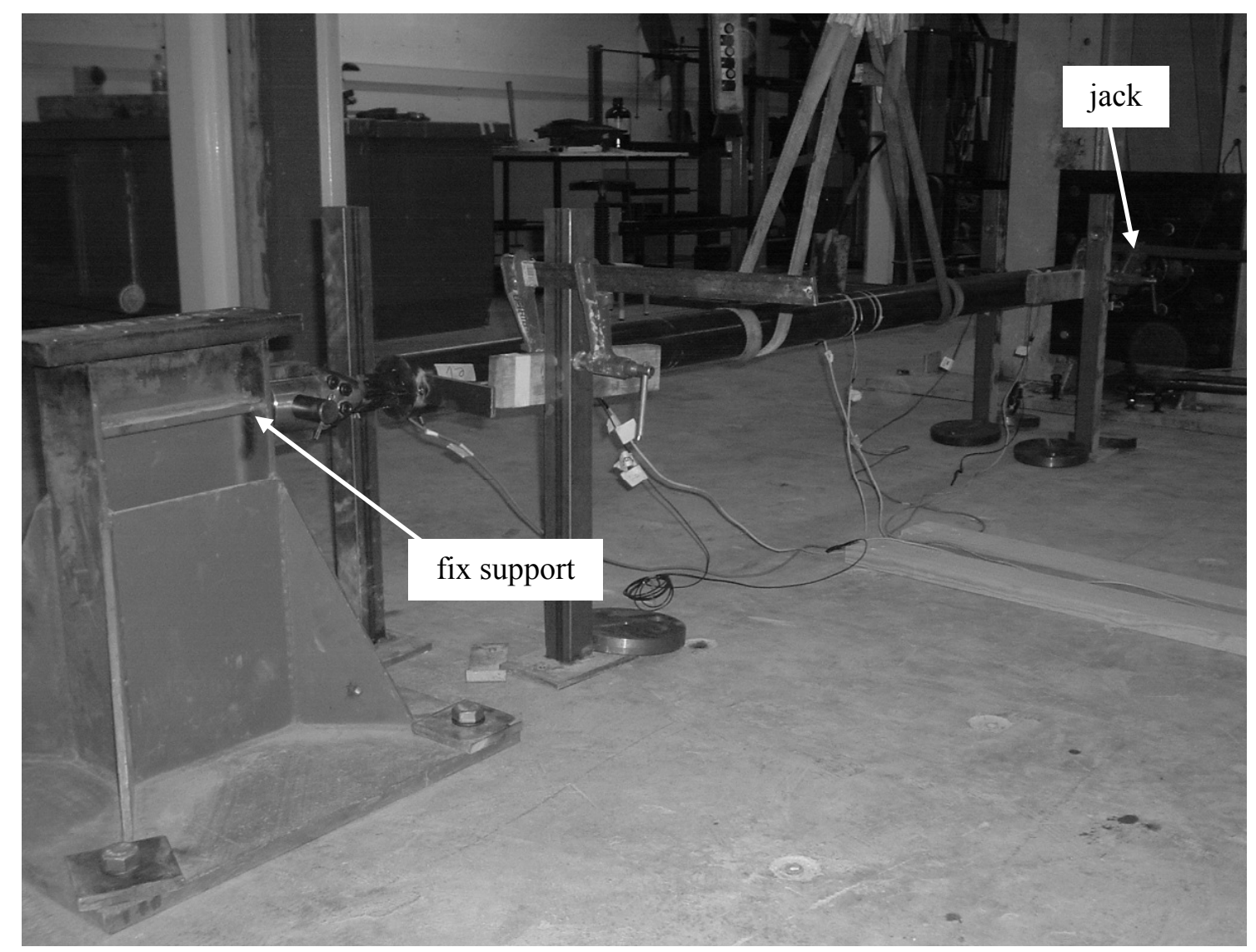

Figure 11. Testing rig in the University of Girona [Palazzo et al., 2011]

Figure 11 shows that the tested device is connected in one of their ends to a fixed support while the other end is connected to a jack; its motion constitutes the imposed axial displacement.

In the core and in the outer tube the steel type is S275 [EN 10025, 2002], whose nominal yielding point and ultimate strength are 275 and $410 \mathrm{MPa}$, respectively; coupon tests were conducted, providing average yielding points equal to $307 \mathrm{MPa}$ (devices D1 \& D2) and to $300.5 \mathrm{MPa}$ (devices D3 \& D4) and average ultimate strength equal to $427 \mathrm{MPa}$ (devices D1 \& D2) and to 423.63 MPa (devices D3 \& D4). No tests about the Young's modulus and the Poisson's ratio were conducted, nominal values were considered instead; such values are $210 \mathrm{GPa}$ and 0.3 , respectively. The compressive strength and the deformation modulus of the mortar were determined by testing; the average obtained values were $39.92 \mathrm{MPa}$ and $17.52 \mathrm{GPa}$, respectively. The tensile strength and the Poisson's ratio are estimated as 3.99 MPa and 0.2, respectively. 
The imposed displacements law consists of a number of growing-amplitude cycles followed by constant-amplitude cycles that maintained until failure; in this last phase the half-amplitude is $5 \Delta_{\mathrm{y}}$. The values of the yielding displacement $\Delta_{\mathrm{y}}$ are estimated as $3.83 \mathrm{~mm}$ for dissipators D1 and $\mathrm{D} 2$ and $3.37 \mathrm{~mm}$ for dissipators D3 and D4. The first imposed cycles of devices D1 and D2 are displayed in Figure 12; they encompass the first phase (growing-amplitude cycles) and part of the second one (constant-amplitude cycles).

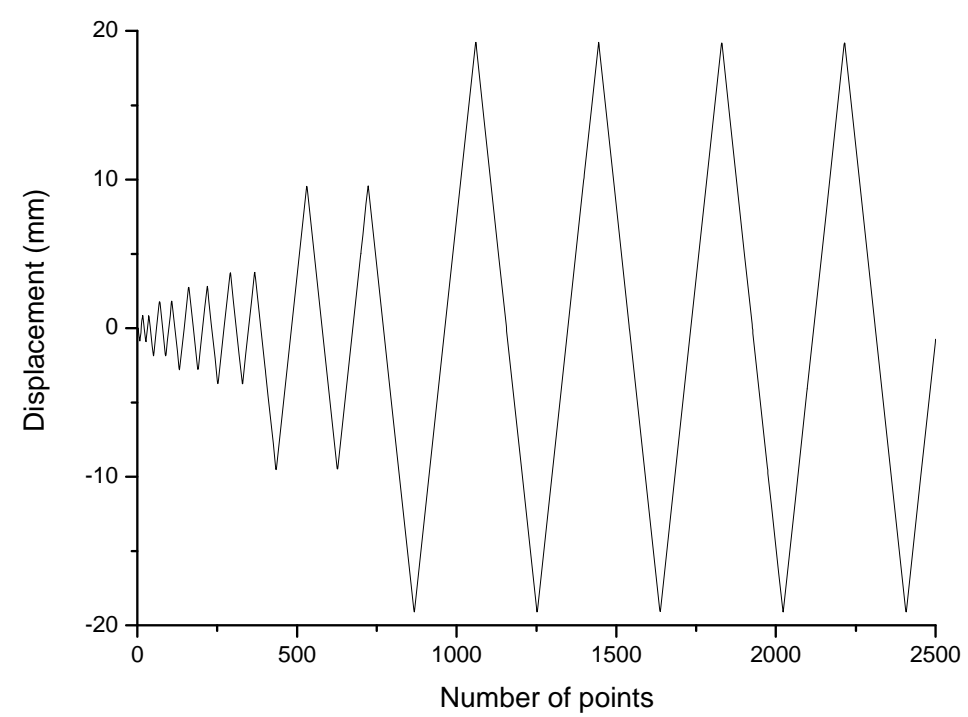

Figure 12. Initial cycles of dissipators D1 and D2 (University of Girona) [Palazzo et al., 2009]

These experiments have been simulated with the proposed model. The plastic behavior of the steel core is described by a kinematic hardening model with hardening modulus $H_{\mathrm{K}}=21 \mathrm{GPa}$; no damage has been considered. In the mortar casing the fracture energy per unit area is $G_{\mathrm{f}}=0.104$ $\mathrm{N} / \mathrm{mm}^{2}$ and the characteristic length $l^{*}$ is equal to the geometric average of the sides of the finite element [Oliver, 1989]. The interface is considered as an air gap; in the contact model the friction coefficient is $\kappa=0.1$, the directionality is isotropic and there is no limit in the transfer of shear stresses. The discretization period of the imposed displacement history (see Figure 12) is $\Delta t=0.05 \mathrm{~s}$. In the explicit integration the time increment is equal to the ratio between the propagation velocity of the shear wave inside the steel and the length $l^{*}$ of the finite element [Abaqus, 2006].

The devices have been discretized with 8-node hexahedron Lagrangian elements. Taking advantage of the symmetry of the tested braces, only half length of the each device is modeled; one of their ends is fully clamped while the other one is transversally free while the axial displacement is imposed to the core. The circular cross sections depicted in Figure 10 have been replaced by an equivalent square geometry to ease the mesh generation and to avoid having finite elements with high aspect ratios. Since the areas of the steel core and of the mortar casing are the same in both cases, this modification does not alter significantly the structural behavior. Aiming also to obtain a regular mesh, the outer steel has been homogenized to mortar.

Figure 13 shows a comparison between the experimental and numerical hysteresis loops of device D1. Given the appearance of the experimental yielding branches, kinematic hardening was considered for the numerical modeling of the steel core. Plots from Figure 13 show a satisfactory agreement; the pinching effect observed in the experimental results is generated by gaps in the end connections (Figure 10). Both the experimental and the numerical results show that the 
yielding and maximum compressive forces are slightly higher than the tensile ones; this difference is due to the mortar casing contribution caused by the shear stress transfer generated during the buckling of the core. Conversely, in Figure 8 both yielding points are alike since the core is significantly stockier. The mortar did not experience any damage; this result fits the after-test observations [Palazzo et al., 2009; Palazzo et al., 2011].

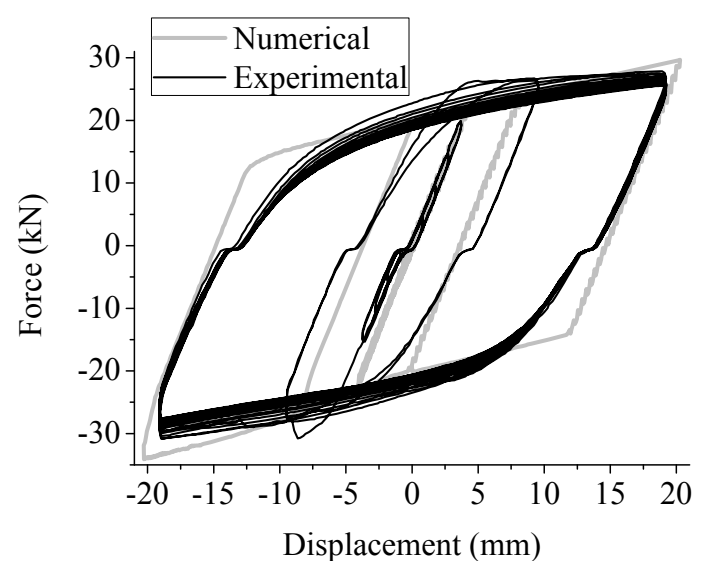

Figure 13. Numerical and experimental hysteresis loops of dissipator D1 (University of Girona)

Figure 14 shows a comparison between an experimental and a numerical hysteresis loop of device D3 corresponding to the cycles with higher amplitude (5 $\Delta_{y}$, see Figure 12). The numerical and experimental values of the dissipated energy (area encompassed by the loop) are 4.624 and 4.477 $\mathrm{kNm}$, respectively; this agreement is considered satisfactory.

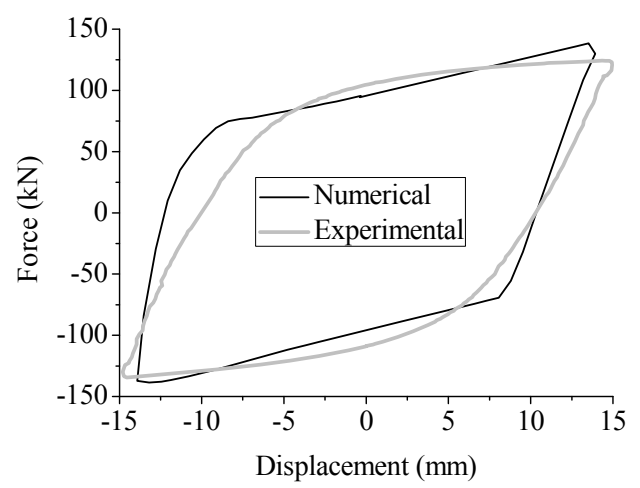

Figure 14. Numerical and experimental hysteresis loop of dissipator D3 (University of Girona)

\subsection{Tests in the University of California}

Two pairs of nominally-identical and full-scale buckling-restrained brace subassemblages (termed $1 \mathrm{G} \& 2 \mathrm{G}$ by one side, and $3 \mathrm{G} \& 4 \mathrm{G}$ by the other side) were tested in the University of California, San Diego [Newell, Uang, Benzoni, 2006]. Figure 15 describes the tested devices; they are composed of a steel surrounded by a grout-filled square tube. The core of devices $1 \mathrm{G} \&$ $2 \mathrm{G}$ is a flat plate while the one of devices $3 \mathrm{G} \& 4 \mathrm{G}$ has a cruciform cross-section. Table 2 displays the values of the main geometrical parameters of the specimens. 


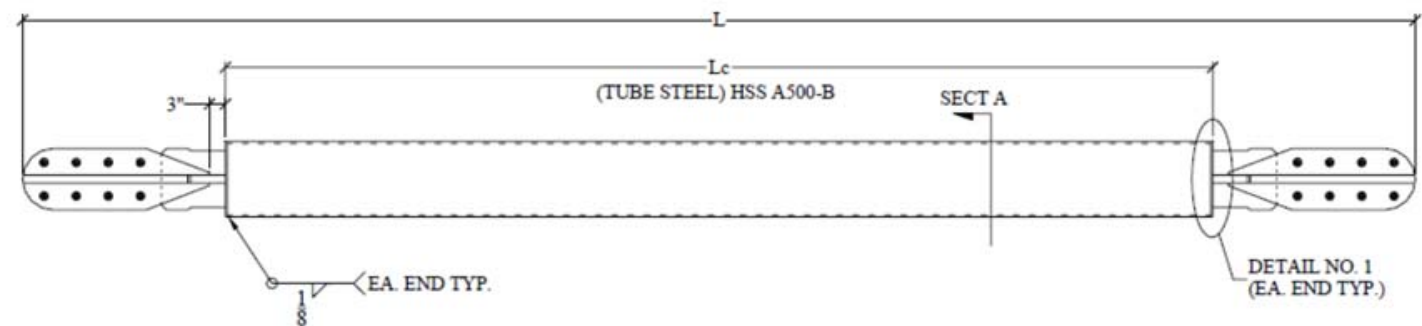

(a) Overall view

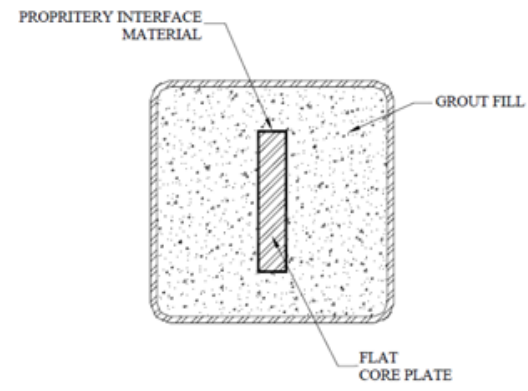

(b) Cross-section of devices $1 \mathrm{G} \& 2 \mathrm{G}$

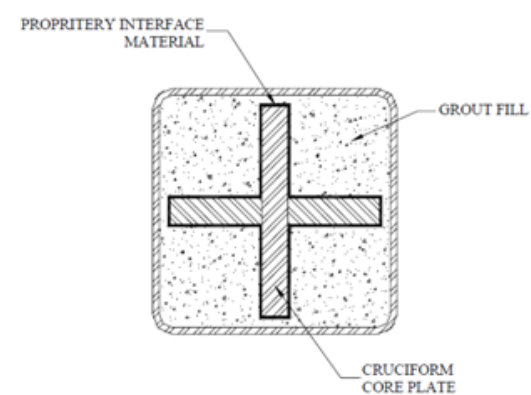

(c) Cross-section of devices $3 \mathrm{G} \& 4 \mathrm{G}$

Figure 15. Devices tested in the University of California [Newell, Uang, Benzoni, 2006]

Table 2. Main geometrical parameters of prototypes $1 \mathrm{G}, 2 \mathrm{G}, 3 \mathrm{G}$ and $4 \mathrm{G}(1 \mathrm{in}=25.4 \mathrm{~mm})$

\begin{tabular}{cccccc}
\hline Devices & $\begin{array}{c}L \\
\text { (in) }\end{array}$ & $\begin{array}{c}L_{\mathrm{c}} \\
\text { (in) }\end{array}$ & $\begin{array}{c}L_{\mathrm{y}} \\
\text { (in) }\end{array}$ & $\begin{array}{c}\text { tube } \\
\text { (in) }\end{array}$ & $\begin{array}{c}\text { core } \\
\text { (in) }\end{array}$ \\
\hline $1 \mathrm{G} \mathrm{\&} 2 \mathrm{G}$ & $260-1 / 8$ & $184-3 / 8$ & $132-1 / 2$ & $14 \times 14 \times 5 / 16$ & $8 \times 1-1 / 2$ \\
$3 \mathrm{G} \mathrm{\&} \mathrm{4G}$ & $250-3 / 16$ & $164-7 / 16$ & $144-7 / 16$ & $16 \times 16 \times 5 / 16$ & $9-3 / 4 \times 9-3 / 4 \times 1-1 / 2$
\end{tabular}

In Table $2, L_{\mathrm{y}}$ is the length of the yielding segment, i.e. the one whose cross-section is shaped as described by Figure 15(b) or Figure 15(c).

The specimens underwent both longitudinal and transversal imposed displacements; only the axial components are considered for simulation. The loading protocol was a combination of those stated in [AISC, 2005] and in FEMA 450 [FEMA, 2003]. Such loading sequences are established in terms of $\Delta_{b y}$ and $\Delta_{b m} . \Delta_{b y}$ is the yielding displacement, and $\Delta_{b m}$ corresponds to the design story drift; $\Delta_{\text {bm }}$ was assumed as $5 \Delta_{\text {by }}$.

The steel type of the core is A36 [ASTM, 2008], whose actual average yielding point and ultimate strength are 37.5 and $70.3 \mathrm{ksi}$, respectively $(1 \mathrm{ksi}=6.895 \mathrm{MPa})$; such values have been obtained from coupon tests. In the outer tube the steel type is A500 Grade B [ASTM, 2010]. The compressive strength of the grout was obtained by testing; the average value at 28 days was 8825 psi. The deformation modulus, the tensile strength and the Poisson's ratio are estimated as 2541 ksi, 883 psi, and 0.2 , respectively.

These experiments have been simulated with the proposed model. In the steel core the modulus of elasticity is taken as $210 \mathrm{GPa}$ and the plastic behavior is described by an isotropic and kinematic hardening model with hardening moduli $H_{\mathrm{K}}=H_{\mathrm{I}}=21 \mathrm{GPa}$; no damage has been considered. In the grout fill the fracture energy per unit area is $G_{\mathrm{f}}=0.242 \mathrm{~N} / \mathrm{mm}^{2}$ and the characteristic length $l^{*}$ is equal to the side of the finite element. The sliding interface is considered as an air gap; in the contact model the friction coefficient is $\kappa=0.1$, the directionality is isotropic and there is no limit 
in the transfer of shear stresses. In the explicit integration the time increment is equal to the ratio between the propagation velocity of the shear wave inside the steel and the length of the finite element [Abaqus, 2006].

As in the simulation of the experiments carried out in the University of Girona, the devices have been discretized with 8-node hexahedron Lagrangian elements; taking advantage of the symmetry of the devices, only half of the total length is modeled. Conversely to the discretization of the devices tested in the University of Girona, the outer steel has not been homogenized to grout.

Figure 16 shows the experimental hysteresis loops of specimens $1 \mathrm{G}$ and $3 \mathrm{G}$ and Figure 17 displays the corresponding numerical simulations.

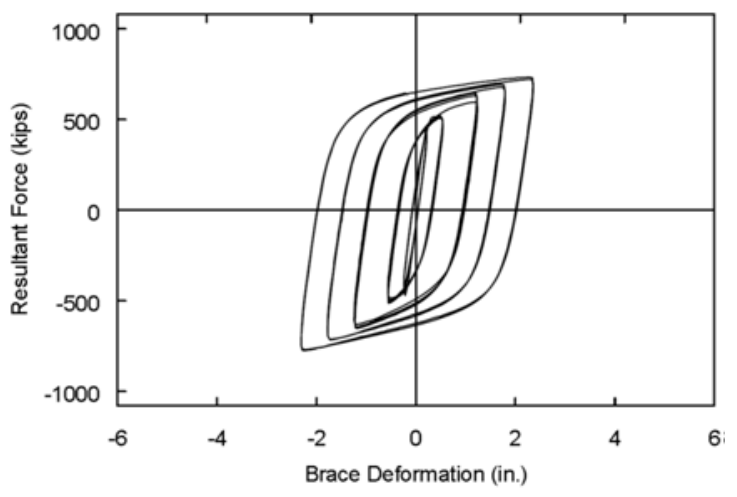

(a) Device 1G

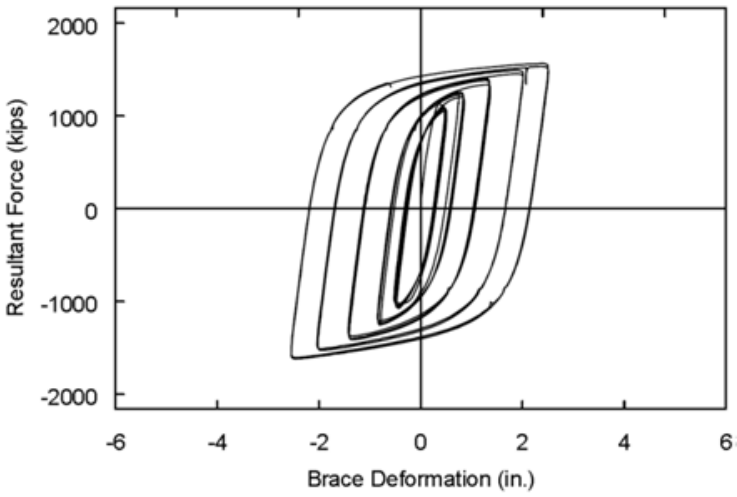

(b) Device 3G

Figure 16. Experimental hysteresis loops of devices tested in the University of California [Newell, Uang, Benzoni, 2006] $(1 \mathrm{kip}=4448 \mathrm{~N} ; 1$ in $=25.4 \mathrm{~mm})$ 


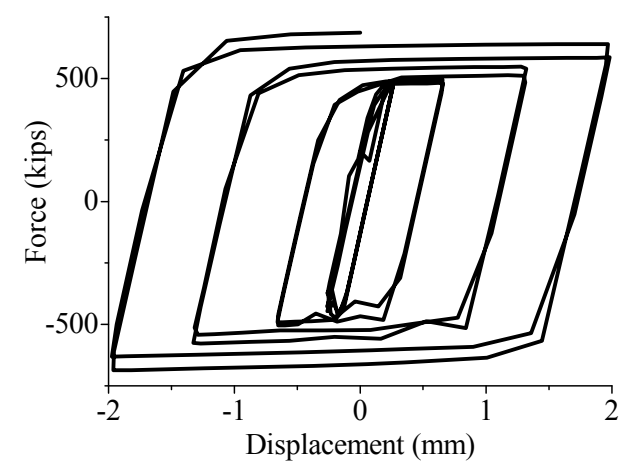

(a) Device 1G. Isotropic hardening

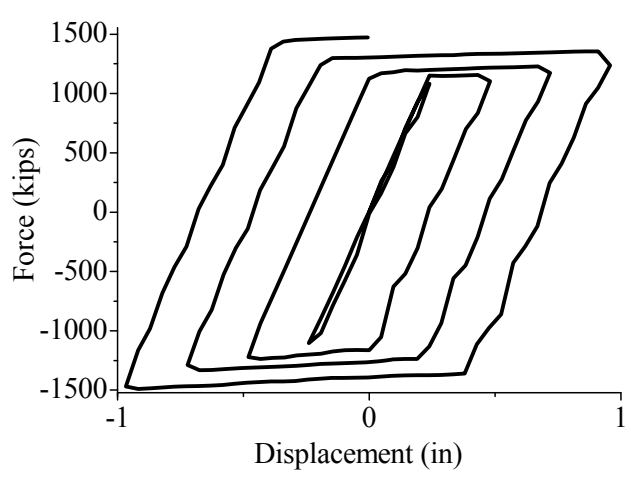

(c) Device 3G. Isotropic hardening

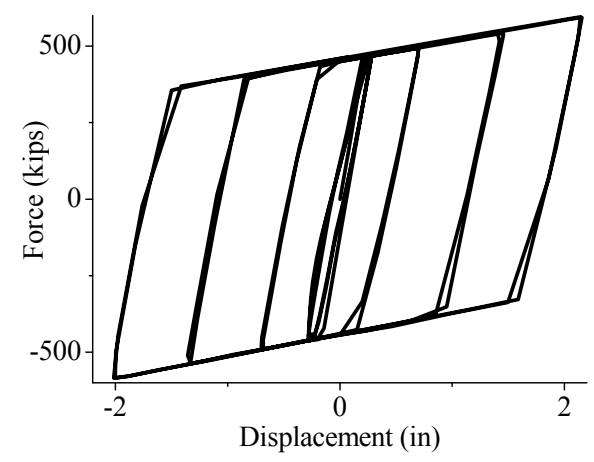

(b) Device 1G. Kinematic hardening

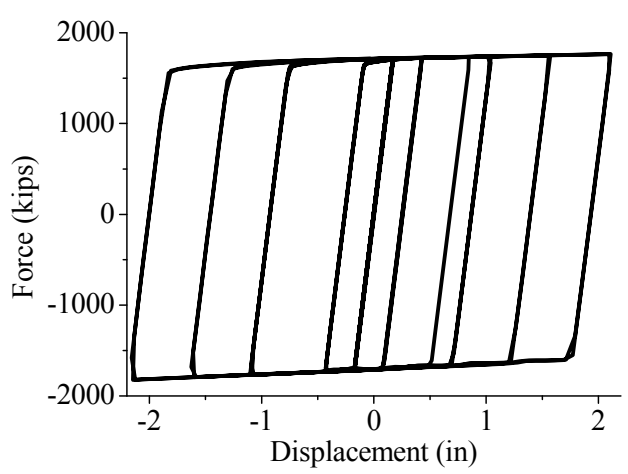

(d) Device 3G. Kinematic hardening

Figure 17. Numerical simulation of tests in the University of California $(1 \mathrm{kip}=4448 \mathrm{~N} ; 1 \mathrm{in}=25.4 \mathrm{~mm})$

Comparison between the experimental and the numerical results showed in Figure 16 and in Figure 17 shows a satisfactory agreement. In both Figures, for device $3 \mathrm{G}$ the maximum and yielding values of compressive and tensile forces are near alike while for device $1 \mathrm{G}$ the compressive forces are higher. This dissimilarity can be explained the big slenderness of the core of device $1 \mathrm{G}$ in its weak direction (see Figure 15.b).

\section{Conclusions}

An accurate and continuum mechanics-based numerical model of the cyclic behavior of dissipative buckling-restrained braces is built. The proposed algorithm is oriented to devices composed of a steel core embedded in a mortar or steel casing. The behavior of the steel core is described by a model with a large displacement formulation and including multiaxial plasticity and isotropic damage. The behavior of the mortar is described by an isotropic damage model and the sliding behavior of the interface is described by a contact penalty model. These three models are implemented in the Abaqus software package; an explicit formulation is chosen because of the ill-conditioning of the stiffness matrix due to the penalty formulation of the contact problem. The integration of the models of the mortar, the steel and the interface guarantees the stability of the energy balance. The ability of the individual and integrated models to reproduce the cyclic behavior of buckling-restrained braces is verified in a number of representative situations. As well, the accuracy of the proposed algorithm is satisfactorily checked by comparison with two sets of experimental results.

Further research will focus on extensive use of the proposed model to allow for accurate and innovative design of buckling-restrained braces, mainly for mass use in developing countries. The 
main objective will be to gain a deep understanding of the integrated core-casing buckling behavior; preliminary results show that slender cores generate relevant shear stress transfer to the core while this phenomenon is less noticeable for stockier cores. It is expected that the proposed model will allow designing devices more slender and less costly than the commercially available ones.

\section{Acknowledgements}

This work has received financial support from the Spanish Government under projects CGL2008-00869/BTE and CGL2011-23621.

\section{References}

[1] ABAQUS analysis user's manual version 6.6. Pawtucket, RI: Hibbitt, Karlsson \& Sorensen, Inc. 2006.

[2] AISC. Seismic Provisions for Structural Steel Buildings, American Institute of Steel Construction, Chicago, 2005.

[3] Armero F, Oller S. A general framework for continuum damage models. I. Infinitesimal plastic damage models in stress space. II. Integration algorithms, with application to the numerical simulation of porous metals. International Journal of Solids and Structures 2000; 37:7409-7436 (I) 7437-7464 (II).

[4] ASTM A36 / A36M - 08 Standard Specification for Carbon Structural Steel. American Society for Testing of Materials 2008.

[5] ASTM A500 / A500M - 10a Standard Specification for Cold-Formed Welded and Seamless Carbon Steel Structural Tubing in Rounds and Shapes. American Society for Testing of Materials 2010.

[6] Astrella M, Whittaker A. The Perfomance-Based Design Paradigm. MCERR Report MCEER-05-0011 2005.

[7] Black C, Makris N, Aiken L. Component Testing, Seismic Evaluation and Characterization of Buckling-Restrained Braces. Journal of Structural Engineering ASCE 2004; 130:329-337.

[8] Castro-Medina JC. Numerical modelling of the structural behaviour of buckling-restrained braces (in Spanish). Doctoral Dissertation. Technical University of Catalonia, Barcelona (Spain) 2011.

[9] Choi H, Kim J. Energy-based seismic design of buckling-restrained braced frames using hysteretic energy spectrum. Engineering Structures 2006; 28:304-311.

[10] Chou CC, Chen SY. Subassemblage tests and finite element analyses of sandwiched buckling-restrained braces. Engineering Structures 2010; 32:2108-2121.

[11] Clark P, Aiken I, Kasai K, Ko E, Kimura I. Design Procedures for Buildings Incorporating Hysteretic Damping Devices. Proceedings of the 68th Annual Convention. Structural Engineers Association of California. Sacramento 1999; 355-371.

[12] D'Aniello M, Della Corte G, Mazzolani FM, Landolfo R. Steel Buckling-Restrained Braces. In: Seismic upgrading of RC buildings by advanced techniques - The ILVA-IDEM Research Project. Polimetrica Publisher. Italy, 179-223 2006.

[13] EN 10025. Hot rolled products of structural steels. European Committee for Standardization, 2002.

[14] EN 206-1. Concrete - Part 1: Specification, performance, production and conformity. European Committee for Standardization, 2000.

[15] Fahnestock LA, Sause R, Ricles JM. Seismic analysis and design of buckling-restrained braced frames. 5th International PhD Symposium in Civil Engineering. Walraven, Blaauwendraad, Scarpas \& Snijder (eds) Taylor \& Francis 2004. 
[16] FEMA 450, NEHRP Recommended Provisions for Seismic Regulations for New Buildings and Other Structures. Federal Emergency Management Agency 2003.

[17] Housner GW, Bergman LA, Caughey TK, Chassiakos AG, Claus RO, Masri SF, Skelton RE, Soong TT, Spencer BF, Yao JTP. Structural Control: Past, Present, and Future. Journal of Engineering Mechanics ASCE 1997; 123:897-971.

[18] Iwata M. Applications-Design of Buckling-Restrained Braces in Japan. 13th World Conference on Earthquake Engineering. Paper No. 3208. Vancouver Canada 2004.

[19] Kasai K, Kibayashi M. JSSI manual for building passive control technology. PART-1 Manual contents and design/analysis methods. 13th World Conference on Earthquake Engineering. Paper No. 2989. Vancouver Canada 2004.

[20] Kibayashi M, Kasai K, Tsuji Y, Kikuchi M, Kimura Y, Kobayashi T, Nakamura H, Matsuba Y. JSSI manual for building passive control technology. PART-2 Criteria for implementation of energy dissipation devices. 13th World Conference on Earthquake Engineering. Paper No. 2990. Vancouver Canada 2004.

[21] Lee K, Bruneau M. Energy Dissipation of Compression Members in Concentrically Braced Frames: Review of Experimental Data. Journal of Structural Engineering ASCE 2005; 131:552-559.

[22] López WA, Gwie DS, Lauck TW, Saunders M. Structural Design and Experimental Verification of a Buckling-Restrained Braced Frame System. Engineering Journal 2004; 41(4):177-186.

[23] Lubliner J, Oliver J, Oller S, Oñate E. A plastic damage model for concrete. International Journal of Solids and Structures 1989; 25(3):299-326.

[24] Martelli A. Modern seismic protection systems for civil and industrial structures. An advanced approach to earthquake risk scenarios, with applications to different European towns. Downloadable at http://www.samco.org/network/download_area/paper_martelli.pdf 2006.

[25] Newell J, Uang CM, Benzoni G. Subassemblage testing of core brace buckling-restrained braces (G Series). University of California San Diego. Report No. TR-2006/01 2006.

[26] Oliver J. A Consistent Characteristic Length for Smeared Cracking Models, International Journal for Numerical Methods in Engineering 1989; 218:461-474.

[27] Palazzo G, Crisafulli F, López Almansa F, Cahís X. Análisis numérico experimental de barras de pandeo restringido. XIX Jornadas Argentinas de Ingeniería Estructural. Mar del Plata Argentina 2006.

[28] Palazzo G, Crisafulli F. Estudio Comparativo de Distintos Disipadores por Fluencia en Base a los Requerimientos Establecidos en Distintas Normas. XXXI Jornadas Sud-Americanas de Ingeniería Estructural. Mendoza. Argentina 2004.

[29] Palazzo G, López-Almansa F, Cahís X, Crisafulli F. A low-tech dissipative buckling-restrained brace. Design, analysis, production and testing. Engineering Structures 2009; 31:2152-2161.

[30] Palazzo G, López-Almansa F, Cahís X, Crisafulli F. Theoretical and Experimental Analysis of Dissipative Buckling Restrained Braces. CIMNE Monograph Report IS-64 2011.

[31] Sabelli R, Aiken I. US building-code provisions for buckling-restrained braced frames: basis and development. 13th World Conference on Earthquake Engineering. Paper No. 1828 Vancouver Canada 2004.

[32] Sabelli R, Mahin S, Chang C. Seismic Demands on Steel Braced Frame Buildings with Buckling-Restrained Braces. Earthquake Engineering Research Center. University of California http://nisee.berkeley.edu/library 2002.

[33] Sabelli R, Mahin SA, Chang C. Seismic demands on steel braced-frame buildings with buckling-restrained braces. Engineering Structures 2003; 25:655-666.

[34] Sabelli R, Pottebaum W, Brazier JC, López W. Design of a Buckling-Restrained Braced Frame Utilizing 2005 Seismic Standards. Metropolis \& Beyond 2005. Proceedings of the 
2005 Structures Congress and the 2005 Forensic Engineering Symposium. New York.

[35] Simo JC, Ju JW. Strain and stress-based continuum damage models. I. Formulation. International Journal of Solids and Structures 1987; 23(7):821-840.

[36] Simo JC, Hughes TJR. Computational Inelasticity. Springer, 1998.

[37] Soong T, Dargush G. Passive energy Dissipation Systems in Structural Engineering. John Wiley, 1997.

[38] Tremblay R, Bolduc P, Neville R, De Vall R. Seismic testing and performance of buckling-restrained bracing systems. Canadian Journal of Civil Engineering 2006. 33:183-198.

[39] Tremblay R, Degrange G, Blouin J. Seismic Rehabilitation of a Four-Storey Building with a Stiffened Bracing System. 8th Canadian Conference on Earthquake Engineering. Canadian Association for Earthquake Engineering Vancouver 549-554 1999.

[40] Tremblay R, Lacerte M, Christopoulos C. Seismic Response of Multi-Storey Buildings with Self-Centering Energy Dissipative Steel Braces. Journal of Structural Engineering ASCE 2008; 134:108-120.

[41] Tsai KC, Lai JW, Hwang YC, Lin SL, Weng CH. Research and application of double-core buckling-restrained braces in Taiwan. 13th World Conference on Earthquake Engineering. Paper No. 2179 Vancouver Canada 2004.

[42] Wada A, Nakashima M. From infancy to maturity of buckling-restrained braces research. 13th World Conference on Earthquake Engineering. Paper No. 1732 Vancouver Canada 2004.

[43] Watanabe A, Hitomi Y, Saeki E, Wada A, Fujimoto M. Properties of Brace Encased in Buckling-Restraining Concrete and Steel Tube. Proceedings of the Ninth World Conference on Earthquake Engineering. Vol. IV. 719-724. Japan Association for Earthquake Disaster Prevention. Tokyo-Kyoto. Japan 1988.

[44] Wriggers P. Computational Contact Mechanics. Springer-Verlag, 2006. 